Bryn Mawr College

Scholarship, Research, and Creative Work at Bryn Mawr College

2019

Ethics of care, emotional work, and collective action of solidarity: the Patronas in Mexico

Verónica Montes

María Dolores Paris Pombo

Let us know how access to this document benefits you.

Follow this and additional works at: https://repository.brynmawr.edu/soc_pubs

Part of the Sociology Commons

This paper is posted at Scholarship, Research, and Creative Work at Bryn Mawr College. https://repository.brynmawr.edu/soc_pubs/19

For more information, please contact repository@brynmawr.edu. 


\title{
Ethics of Care, Emotional Work, and Collective Action of Solidarity: The Patronas in Mexico
}

\author{
Verónica Montes
}

María Dolores París-Pombo

In this paper, we examine the mobilization of the Patronas, a group of Mexican women who have fed thousands of Central American migrants over the past two decades. We argue that the Patronas' work of feeding and caring for migrants goes beyond essentializing these women's work as just housewives, mothers, and caregivers. Furthermore, we assert that through these care activities, the Patronas exert a feminist ethics of care that is understood as a set of practices based on trust, reciprocity, and solidarity. The Patronas' praxis of caring for the migrants resonates with people and attracts hundreds of volunteers to join these women's emotional and nurturing work leading these women and volunteers to participate in a political practice of solidarity. In this paper, we articulate three key findings: (1) the interplay between the Patronas' emotional work and the ethics of care, (2) the emergence of a collective act of solidarity around the Patronas' caring work that leads hundreds of volunteers to visit these women and join them, and (3) the kitchen as a place where the collective act of solidarity begins and where the Patronas experience their personal transformation. Drawing on ethnographic fieldwork, this study contributes to further our understanding of the interplay between Latin American women's participation in social movements, emotional work in these movements, and the ethics of care.

\section{Keywords: Women's collective action, solidarity movements, ethics of care, emotional work, and Las Patronas.}

AUTHORS' NOTE: We would like to thank Margaret Walton-Roberts for all her support, her editorial staff, and three anonymous reviewers for their extremely helpful comments on earlier drafts of this article. Our deepest gratitude to the Patronas who generously opened their shelter's door and shared their histories. The first author's research time for this study began during her tenure as an Andrew W. Mellon Postdoctoral Teaching Fellow at the University of Southern California in the Department of Sociology and with the Center for the Study of Immigrant Integration. Correspondence concerning this article should be addressed to Veronica Montes, Bryn Mawr College, 101 North Merion Ave. Bryn Mawr, PA 19010-2899, USA; e-mail: vmontes@brynmawr.edu. María Dolores París-Pombo, El Colegio de la Frontera Norte, Km. 18.5 Escénica Tijuana-Ensenada, San Antonio del Mar, Tijuana, Baja California, Mexico. E-mail: mdparis@colef.mx 


\section{Introduction}

The Patronas (The Patrons) is a group of defenders of migrants' human rights that was formed by women volunteers from the community of La Patrona in the southern state of Veracruz, Mexico. For 23 years, these women have fed thousands of Central American migrants who have passed through La Patrona in attempts to reach the United States. The Patronas began their work of feeding migrants in 1995 when sisters from the Romero family were moved by a gesture of compassion and gave up bread and milk they had just bought to unknown migrants who were traveling on top of a freight train known as la bestia (the beast). This train passes through the community of La Patrona and connects the south and north of Mexico. Approximately 2,000 miles long, it has served for more than two decades as a means of transportation to migrants in their trek to the US-Mexico border.

During the first ten years, these women of humble rural origins financed the feeding of thousands of Central American migrants with their scarce resources. De Nadie (No-One's) is the first documentary (Dirdamal 2005) where the Patronas became public, and its screening in 2005 marked a turning point in these women's work as it brought hundreds of volunteers and donations to help continue the work of feeding the growing number of migrants. In the heyday of the Central American migration influx to the US from the early 2000s to 2013, the Patronas' work consisted of three cooking shifts in which women cooked up to 60 kilograms (141 pounds) of rice and beans to feed approximately 1,000 migrants daily. Today, the Patronas continue caring for migrants, not only by feeding them but also by providing shelter to combat the increasing challenges migrants face during their perilous journey to the US. Thus, what started with a feeling of compassion has evolved into the collective actions of thousands of volunteers, both national and international, that 
have come to the community of La Patrona, not only to feed the migrants, but also to fight for social justice for migrants.

This article examines how these women's work of feeding and caring for migrants has been sustained uninterruptedly for 23 years. It also looks at why hundreds of volunteers from Mexico and all over the world come to La Patrona with the only purpose of participating in this collective action of solidarity. The guiding questions for this article are: What explains the Patronas' long-standing work of feeding and caring for Central American migrants, and what has sustained their emotional work? Why are these migrants so important to the Patronas? Why has this caring work created so much sympathy and support from both national and international volunteers? Finally, what has been the personal impact of this work on each of these women known as the Patronas?

The Patronas' work is part of what scholars have begun referring to as humanitarian care practice, where caring for an 'Other' becomes essential in nurturing social bonds of empathy to cultivate moral solidarities towards those experiencing social suffering (Wilkinson and Kleinman 2016). In this sense, the main argument in this article is that by caring for and feeding these migrants, the Patronas not only reject the role of being silent bystanders in the pervasive violence in Mexico but more importantly, they demonstrate the possibility of recognizing our vulnerability in others. Thus, feeding 'Others' can be interpreted as not only a kind of women's emotional work but also as a catalyst for collective action, where hundreds of people coalesce and participate in a social transformation project.

Our examination of the Patronas' work contributes to the literature on Latin American women's participation in social movements (Chinchilla and Hass 2007, Rodriguez Castro, Pini, and Baker 2016, Stephen 1997, Schroeder 2006, Jelin 1994, Jaquette 2009, Maier and Lebon 2010) 
and particularly the role that emotions play in such movements (Jasper 2011, Hercus 1999, Pile 2010, Arenas 2015). Our work also contributes to the literature on the spatiality of gender practices (Bruzzone 2017, Brickell 2012, Meah 2014). In Latin America, the first studies on women's participation in social movements shed light on the way these women's gender roles as mothers legitimize their political participation in the public sphere (Bosco 2006, Bejarano 2002). By appealing to traditional gender roles of not only mothers but also of wives and daughters, these women legitimize their presence outside their traditional private domain (Wright 2008, 2014, Bruzzone 2017, Wright 2005). Thus, drawing on ethnographic fieldwork conducted in the community of La Patrona, this study advances the understanding of the interplay between Latin American women's participation in social movements, emotional work in these movements, and ethics of care.

As a way to introduce the reader to the complex plight that Central American migrants endure while crossing Mexican territory to reach the US-Mexican border and the significance of the Patronas' caring and emotional work in such adverse context, we begin by introducing the research context section. We then discuss the theoretical foundations of this study by exploring how the emotional work performed by the Patronas could be understood as a direct response to the valorization of migrants' lives, particularly in the current neoliberal context, where the value of life in general and that of certain minority groups such as migrants, in particular, become worthless. We next describe the participatory research methodology used to underline the nuances of the Patronas' emotional work. In the empirical section, we articulate three key findings: the interplay between the Patronas' emotional work and the ethics of care; the emergence of a collective act of solidarity around the Patrona's caring work; and the kitchen as a place where the collective act of 
solidarity begins and where the Patronas experience their personal transformation. We conclude this article by articulating some final remarks about the significance of this study.

\section{Research Context}

The community of La Patrona is located in the municipality of Amatlán de los Reyes in the state of Veracruz, Mexico. It is a rural community with a population of approximately 4,000 inhabitants. Most people in the community own small, private plots of land where they grow sugarcane as the main crop. The global decline in sugar prices, the privatization of the Mexican agroindustry, and the shrinking of national subsidies and public services have severely impacted the family economy, creating strong pressure to diversify household income (Aguilar-Rivera et al. 2012).

As in many other developing countries, the implementation of neoliberal policies in rural areas has created pressures in peasant families to produce more to subsist (Rodriguez Castro, Pini, and Baker 2016). Women in La Patrona have always combined their role of reproducing with farm labor, but in a neoliberal economy, these women also sell their labor as either domestic workers in the municipality of Amatlan or as sugar cutters in the sugar-production companies to contribute to their family economy. In the case of men, they perform farm labor for those who have not yet sold their plots of land, they sell their labor as wage earners in an edible-oil processing plant located near La Patrona, or they end up migrating to the US.

As in many rural regions in Mexico, when agriculture no longer provides a livelihood, men migrate while women stay home and take care of extended families. In this regard, migration and mobility in the context of La Patrona have been shaped by social norms and gender roles (Hanson 2010). Unlike other regions in Veracruz, the number of people from La Patrona leaving for the US 
is low. Yet its inhabitants have experienced the contradictions of international migration as they have witnessed the crossing of thousands of Central American migrants through their community. La Patrona is situated on a principal migratory route that crosses the Mexican territory from south to north. A freight train crosses through this community that has been used by thousands of Central American migrants to reach the US since the 1990s.

For the thousands of migrants traveling on the train, the short passage through La Patrona is a brief respite of solidarity in the face of a predatory system in their journey along the railroad. Gangs and criminal organizations have taken possession of the train stations and dedicate themselves to extorting, assaulting, and raping migrants (Martínez 2013). Violence against migrants even includes throwing migrants from moving trains if they refuse to pay. The migrants' trips on the train have become a profitable business for private groups associated with police and railway workers. Migrants are abducted and exploited in criminal and sexual markets along the migratory route between the southern and northern borders of Mexico (Paris 2017, Martínez 2013). For example, human rights organizations have demonstrated that mass abductions have become a permanent, large-scale extortion system against migrants in Mexico (Migrantes 2016). The purpose of these abductions is to obtain ransoms from the migrants' families at home or in the US. When family members cannot or refuse to pay the ransom, they are beaten, tortured, and forced to join criminal organizations. Some are killed. For migrant women, girls, boys, and teenagers, abduction commonly implies becoming involved in human trafficking and sexual exploitation networks (Casillas 2011).

Wendy Vogt (2013) points out, 'While in route to becoming productive laborers abroad, migrants are transformed into particular types of commodities that may both gain and lose value within local conditions' (766). Neoliberal politics implemented in Mexico and Central America 
for the last three decades has devastated the region's economies and created a wide sector of disposable people (Green 2011). Unable to survive, this population is forced to move north in hopes of joining US labor markets. In this context, migrants are made vulnerable by their economic and legal marginalization and by their forced dislocation. Their exploitation results from their powerlessness, the potential work in the Global North, and their forced mobility (Paris 2017).

The criminal groups' control over routes and means of transportation all across the Mexican territory has increased concurrently with the implementation of rigid migration and law enforcement. In this adverse context, with the elusive objective of reaching the US, migrants seek to circumvent multiple roadblocks and raids by police and migration officials along the routes, even if that means entering organized crime networks. Considering this predatory migration system, the simple act of feeding migrants day after day for more than two decades has become a symbol of resistance against the commodification of migrants' bodies.

\section{Women's participation in social movement and emotional work}

Some scholars argue that collective action is often instrumentally motivated (Brennan 2004, Lichbach 1996), while others focus on how people join social movements through a shared group identity, strong principles and values, and emotional links (Dunn 2004, Oosterlynck et al. 2016, Arenas 2015). For Jasper (2011, 289), even social movements 'that appear instrumentally interested in power or material benefits are motivated at least as much by a concern for the human dignity that political rights imply.' In this sense, most social struggles and collective identities involve affects that bring people together and construct emotional geographies (Bosco 2006, Arenas 2015). 
Solidarity movements stand out as a peculiar type of social movement. Such movements do not seek material benefits, power, or the recognition of cultural identity. Rather, they mobilize to ensure the survival and dignity of others, who are often unknown foreigners from distant countries (Power and Charlip 2009a). Therefore, they establish translocal and transnational connections characterized by profound affective implications for those involved. These collective actions can be galvanized by political principles or religious beliefs (Chinchilla, Hamilton, and Loucky 2009). Solidarity movements may also result from identification with the victims based on shared experiences (Scholz 2008).

In Weberian terms, the Patronas and other solidarity movements can be considered as an expression of conviction ethics (far from interest or benefit), where the means are the ends of their collective actions. The members' identification with the 'Other' constitutes a radical resistance to the stark violence of criminal groups or corrupt authorities predating Central American migrants who travel through Mexico. We argue that the Patronas' mobilization, as with many groups and organizations fighting for migrants' rights in Mexico, is based on compassion, empathy, and long-term moral emotions (Jasper 2011), as well as ethics of care. These moral emotions stem from feelings of social justice shared by a wide range of volunteers and activists from all over the world who come to visit the Patronas.

The daily work of feeding and caring for the migrants is part of a broad solidarity movement based on a politicized humanism that revolves around convictions of social justice and human rights. The Patronas' emotional work finds sympathy among diverse social groups, such as migrants' families, American and Mexican students, European activists, and civil society. This leads to the development of these groups as a global movement as a result of sharing common emotional experiences, intimacy, and 'interconnections' (Oosterlynck et al. 2016, Arenas 2015). 
This is what Dunn (2004) calls 'cultural resonance' or 'emotional resonance.' Through their agency, the Patronas can move wide audiences to act politically (Wright 2010). Their ability to recognize themselves in 'Others' and to resist the violence in Mexico transforms the symbolic meaning of local or global communities. Instead of alienating the migrants (e.g., as travelers or foreigners) and considering them as disposable, the Patronas reaffirm the sense of interdependence and hence the ethical responsibility for caring for the 'Other' (Butler 2004). Thus, by mobilizing social and political sectors outside their community, the Patronas contribute to the construction of 'new forms or relationships, institutions, and actions that enhance mutuality and well-being' (Lawson 2007, 8).

Through their participation in academic and political forums, the Patronas' collective action has galvanized a moral voice (Hondagneu-Sotelo et al. 2004) against the Mexican government's punitive immigration policies, as well as against the extreme predation and widespread violence towards migrants. In this regard, the socio-political practices of the Patronas constitute a 'rehumanization' act of migration. The daily work of cooking, feeding and caring for the needy leads to the Patronas sharing traits with women's social movements of the Global South by responding to the migrant's interpellation of their role as mothers. ${ }^{i}$ In the 1970's and 1980's, motherist-based groups in Latin America organized to protest human rights violations committed by authoritarian regimes. Women mobilized and politicized their networks to defend their right to protect and feed their families and communities (Bejarano 2002, Bosco 2006). Since the 1990's, women's participation in social movements have also revolved around the struggles against neoliberal policies in the region (Chinchilla and Hass 2007, Borland 2007), peasant struggles (Rodriguez Castro, Pini, and Baker 2016), human rights and social justice agendas (Jelin 1994, Maier and Lebon 2010, Stephen 1997), democracy and citizenship (Jaquette 2009, Andrews 2014). 
The Patronas' participation in social movements sheds light on how motivation and ways of mobilization are related to the spatialities of gender in traditional and rural societies (Schütte 2014). The Patronas' appearance on the public scene through their socio-political practices challenges the notions of women being confined to their social reproductive roles as protective, caring, and attentive housewives and mothers (Abbruzzese and Wekerle 2011). Therefore, this collective action demonstrates the articulation of domestic and public spaces, homes, community, and railroads as 'emotional spaces' (Arenas 2015). In this sense, the Patronas transform the kitchen into a public space that leads them to move beyond domesticity. According to Bruzzone (2017, 249), 'Because the Patronas perform as both public and domestic, they explode any binary that would claim, a priori, that publicness and domesticity exist as mutually exclusive...'

Despite not explicitly evoking gendered meanings (Salzinger 2003), we argue that the Patronas' mobilization strategies and discourse contribute to the de-construction of traditional constructs of gender (Taylor 1999, Wright 2008). They do so by transforming feminine-construct activities such as cooking, feeding, caring, and nurturing into a collective activity of solidarity to help the migrants, where not only these women participate, but most importantly hundreds of volunteers join them. Thus, like mother-activist movements in the Global South, the Patronas' public activism defies gendered norms and creates political subjectivities against political repression and economic exploitation (Bosco 2006, Wright 2008). Their cohesion and longstanding work are based on shared emotions of affection and loyalty, the joy of nurturing others, and the politics of empathy (Dunn 2004).

Futhemore, their collective action calls into question the deep-seated patriarchal and gender regimes in institutions such as the family and the Catholic Church. Drawing from our field research and the content analysis of interviews made to the Patronas, it was revealed that to 
maintain autonomy; the Patronas must permanently resist criticism and attempts at control by men in their families, the community, political parties that constantly seek their endorsement, and the church. The humanitarian action of these organized women to provide food for the helpless without the Church's support is disruptive of the traditional passive and subordinate role assigned to women within the framework of these institutions. This collective action of peasant women is also a call to recognize the vulnerability of the body, the institutionalization of care, and the material conditions that sustain life (Butler 2004). Their affective response and the meanings they impart in social movements imply a need to fight against the neoliberal political framework, and against Mexico's structural violence.

Thus, the examination of the Patronas' care work allows us to explore organic forms of care based on collective solidarity and empathy for the vulnerable 'Other.' We argue that the Patronas' work of feeding and caring for migrants goes beyond essentializing these women's work as just housewives, mothers, and caregivers (Sharp 2009, Hankivsky 2014). Furthermore, we assert that through these care activities, the Patronas exert a feminist ethic of care that is understood as a set of practices based on trust, reciprocity, and solidarity. Their work revolves around the reconstruction of social relations that have been eroded by the current individualistic neoliberal system (Wright 2008, Wright 2010). One can understand the Patronas' long-standing work through a lens of the ethics of care. By engaging in such care, these women challenge the neoliberal market logics that intensify the marginalization of care and the disposability (Green 2011) of the 'Other.'

\section{Methods and data}

In this section, we discuss the methodological approach to the role of emotions in solidarity movements. We argue that through participatory research we can analyze processes of empowerment in social mobilization. Participating as volunteers with the Patronas undoubtedly 
allowed us to understand better the effects of emotions in shaping collective actions of solidarity. In this regard, participatory research is also an emotional work, and the capacity to establish connections with social actors can be considered as a resource for knowledge (Sharp 2009, Van Wijnendaele 2014, Arenas 2015).

We visited La Patrona in May 2015. We had previously arranged to visit these women and expressed our interest in learning about their work in helping the migrants. Although this was the first time we visited the Patronas, we were widely familiarized with their work as part of our own individual research agendas, which revolve around issues of migration and Central American migrants in both the US and in Mexico. Like all volunteers who visit the Patronas, we immediately became involved in all kinds of activities related to feeding the migrants upon our arrival, such as chopping vegetables, cooking, washing dishes, washing and filling up the plastic bottles of water, filling up bags of food.

Today, the Patronas' work not only consists of feeding but also providing shelter to the migrants. After winning an award for their documentary based on the Patronas, El tren de las moscas (The Flies' train, 2010), the Spanish producers went back to La Patrona and financed a humble two-story construction consisting of three rooms to house volunteers and migrants. While the volunteers can stay in either of the two small rooms downstairs, the migrants are sheltered upstairs in a mid-size room, where up to twelve people can fit.

In our first day, while waiting for the train to arrive, we started talking to the Patronas and began to know them by name. In the shelter, there were three other volunteers from Mexico City, who had been there for the weekend, and a few Central American migrants. It was time to eat, and we were all invited to take a seat at a large wooden table. Plates with rice, beans, and a piece of chicken were distributed. Without knowing each other, we started chatting and talking 
about where each of us came from. The Patronas' kitchen creates an atmosphere of fraternity where pleasant conversations prevail. The Patronas know how to make each of their visitors feel at home. That afternoon, no train arrived, so we spent the rest of the afternoon chatting with the Patronas.

Between three and four times a day, the distant whistle of the train announces its fastapproaching arrival to the community. For the inhabitants of La Patrona, the long years of listening to this whistle allowed them to distinguish between southbound and northbound trains. When the train is going north, the Patronas prepare to go out and feed the migrants. The moment the Patronas hear the train whistle, the work begins. We hear the whistle, and we are instructed to quickly fetch the boxes where the food bags are, while others are told to push wheelbarrows filled with bottles of water. It takes about five minutes from the moment that we all start loading things until we walk toward the train tracks.

Once on the tracks, we see the freight train known as 'the beast' approaching in the distance. As the train approaches, each of the Patronas takes her position. They move along the separate tracks at about 10 meters from each other. When the train is only a few meters away, migrants hanging from the wagons become visible. The deafening noise of the train mixes with the voices of the Patronas shouting among themselves: 'Run, bring more bags!' and to the migrants: 'Do not get off!' Suddenly, some of the migrants jump off the train and come running in a kind of euphoria trying to grab the bags for themselves. The whole event can last a few minutes, depending on the speed of the train. Other times, if the conductor slows down, it can last longer, and the Patronas and volunteers can feed the migrants without rushing and or risk. The volunteers and migrants are in contact for only a brief moment, but it is precisely that moment where the collective action of solidarity manifests. 
We conducted eight informal, open-ended interviews with the family members of these women, including a husband and a married young daughter. We also interviewed women who were not officially identified as Patronas but rather as helpers, despite frequently helping at the shelter. We filmed and recorded an interview with doña Leo, the mother of four founders of the Patronas. We also interviewed a Honduran male migrant who had recently arrived at the shelter and was waiting to continue north to the US. All of these interviews were in Spanish, and four were fully recorded and transcribed verbatim. During our stay at the shelter, other people were visiting, such as a group of approximately 30 college students from the nearby city of Xalapa, who visited the Patronas for a single day. Volunteers like these students do not show up in La Patrona with empty hands. They bring rice, beans, oil, and, more recently, clothes and shoes for the migrants. In most cases, students organize fundraising campaigns at their colleges prior to visiting the Patronas so that they can bring donations. The Patronas' work has had the greatest resonance among college students. Not only do students visit the Patronas, but college and university campuses regularly invite the Patronas to give lectures. These invitations have allowed some of these women to travel to places such as Italy, Spain, the US, United Kingdom, and Guatemala. As we will discuss later in this paper, it is through these experiences of giving lectures that the Patronas have been able to reflect about the significance that their work feeding the migrants has had on their lives.

In addition to informal conversations with volunteers and college students, which supplemented our interview data, the second's author conducted dozens of interviews with Central American migrants and personnel at different migrant shelters all across Mexico as part of her book project on Central American migrants (Paris 2017). Some material from those interviews is included to better contextualize the current plight in Mexico about the violence experienced by 
Central American migrants while crossing Mexico to reach the US. Our field observations were compared to obtain a richer set of observations that the work of an ethnographer may have missed (Hondagneu-Sotelo et al. 2004). We always approached the Patronas together to ensure that at least one interviewer would closely pay attention to the responses while another would lead the interviews. In addition to our visual documentation through photos and videos, we analyzed the content of twelve newspaper articles and interviews ${ }^{\mathrm{ii}}$ with the Patronas in addition to systematic

reviews of three documentaries based on them. ${ }^{\text {iii }}$ In the following section, we examine key empirical findings of our study.

\section{Ethics of care for the distant 'Other'}

Ethics of care involves values of empathy, responsiveness, attentiveness, responsibility (Lawson 2007), and compassion. For psychologists, compassion is the ability to understand the emotional state of another person and reduces the suffering of others (Engel 2008). The work of feeding the migrants is a gesture of compassion that revolves around alleviating migrants' pain and social suffering. The Patronas' lives become radically entwined with those of distant strangers, and they identify with the precariousness experienced by these migrants. By doing so, these women engage in politics of responsibility (Lawson 2007) as they make choices that matter for the wellbeing of the 'Other.' The work of the Patronas goes beyond the interpersonal and the near and familiar spheres as they care for the distant 'Other.' This caring work becomes a moral responsibility that motivates the Patronas' actions. Bernarda states, 'The day that we did not cook, we felt seriously bad. We said, "There the train comes, and what will we give them [the migrants] now if we do not cook." ' This comment reveals a preoccupation with the precarious situation of those migrants in transit, but most importantly, Bernarda assumes personal responsibility for caring actions for the 'Other.' 
This notion of being morally obligated to protect and care for the migrants stem from the Patronas' religious identity. For these women, the work they perform with the migrants is part of God's project intended for them, as clearly stated by doña Leo: 'I think God put me on that path to help our brothers who come without food, without water.' According to Norma, the Patronas see their work 'as a project started by God, who invited us to take part in it.' It is this religious conviction and their particular way of practicing it that leads these women to engage in what Hondagneu-Sotelo et al. (2004) call a politicized spirituality, referring to those practices where 'the sacred is combined with the secular, the moral with the political' (137), but above all, where 'religion is moving beyond the narrow, private confines of prayer and pews to public venues.' The type of politicized spirituality carried out by the Patronas is clearly illustrated in the following quote from Bernarda: '... From my point of view, I would rather feed them [the migrants] and not to be praying because I am not going to solve anything by praying (...) You have to go out and help where things are rough, don't you?' Religious feelings are important resources for the Patronas' ability to mobilize different social actors in search of solidarity with the migrants and social justice (Wright 2010).

The Patronas are inspired by a 'religion of acts' (Paris 2017), which, unlike the traditional activities that the Catholic Church has advocated for, such as praying, catechism classes, and kermises, the Patronas assure, through their testimonies, that religion can only be expressed by acts. This gives them a degree of empowerment, which we understand as a type of autonomous and sovereign behavior that enables the individual to exercise their own decisions for their own benefit and that of others. It allows them to oppose different attempts at control, as in the case of the town's priest, who tried to benefit from the work of the Patronas and the resources provided by the volunteers, as well as control and subordinate the women's work. By openly challenging 
male-dominated and hierarchical institutions such as the Catholic Church, the Patronas disrupt the traditional passive and subordinate role assigned to women within the community and society. For example, the Patronas continued their movement despite being strongly criticized by males in the community, including their brothers, about their work feeding male migrants. As happened with the Madres de la plaza de Mayo (Mother of the Plaza de Mayo in Argentina), who were called locas (crazy) (Bosco 2006, 363), many males in the community referred to the Patronas as crazy and loose women for feeding men they did not know.

While the strong religiousness and peasant origin of these women are two identity aspects shared by the Patronas, each of these women live and perform their work in a very particular way, as the following quotes illustrate:

It is a very big [sic] emotion because since the moment that person comes because he has already seen you from afar and comes with his hand already stretched out, and at the moment he grabs the bag and instantly tells you, "Thank you mother," and goes on happy. It feels good; it is something nice; you do not know them or anything, and it is a pretty nice connection. (Lorena)

They yell at me, "Bye granny," "Bye, mamacita (mother), may God bless you." (doña Leo)

Their faces show laughter as they say "Thank you mother, may God bless you," and that is the greatest payment you receive. (Norma)

It is through this emotional work where each of the Patronas finds the motivation to continue their daily work of feeding migrants. The practice of this 'everyday religion' (Hagan 2008) has also enabled them to sustain their work during all these years. We next examine how the work has evolved into a collective action of solidarity linked to national and international networks that fight for social justice for migrants. 


\section{The collective action of solidarity}

In Latin America, the first studies on women's participation in social movements shed light on the way these women's gender roles as mothers legitimize their political participation in the public sphere (Bosco 2006, Bejarano 2002). By appealing to the traditional gender roles of mothers, wives, and daughters, these women legitimize their presence outside their traditional private domain (Bruzzone 2017, Wright 2008, 2014, 2011, 2005). In the beginning, compassion led the Patronas to feed the migrants, but it was the experience of an 'outlaw emotion' - in this case, outrage - that allowed these women to build a collective movement of solidarity. Jaggar (1989) uses 'outlaw emotions' to refer to emotions that prompt a gut feeling that something is not right and should be questioned, which could, therefore, lead to action. Bernarda states, 'They kill them [the migrants] as if they were criminals. They have no compassion. Why do they mess with them? Why do they take their lives if they [the migrants] do not mess with anyone?' Bernarda's comment evokes a sense of moral responsibility that motivates her actions and frames the Patronas' commitment toward the wellbeing of the 'Other.'

Both the Patronas and volunteers share the values of compassion and empathy towards the migrant community, but the collective action of solidarity gives cohesion to the activities of caring. In the literature on solidarity movements, solidarity 'is not about our lives but about the lives of others - their right not only to live but to build a new, more just society — and our desire to help them do so' (Power and Charlip 2009b, 4). Thus, the work of feeding the distant 'Other' can be interpreted as not only part of an ethics of care but also as a catalyst for collective action. Precisely, the Patronas' caring work, which is based on emotions of compassion, empathy, and solidarity, resonates with people and makes hundreds of volunteers visit the town to join these women's emotional and nurturing work. In this sense, both the Patronas' and volunteers' caring 
work converge to create a political practice of solidarity where the well-being and caring of the migrants is at the core. The Patronas' praxis of caring for the migrants explains why they have earned so much sympathy and support from volunteers.

In addition to sharing the same values of compassion and empathy, the bonding trust between the Patronas, the volunteers, and the donors has been crucial. Reflecting on why people trust them, Bernarda comments:

Because look, I think that we are working women, we are peasant women, we are sincere women, many politicians have come here to propose things to us, but we say no, no... no, because we already know that is all crap... and people have trusted us, believe in us... and sometimes we say among ourselves, "We have to do things well, as they should be, as God intends."

Bernarda's comment highlights two fundamental points about why people trust the Patronas. First, she situates her social identity as a determining factor in the accumulation of moral capital in front of the volunteers and donors, which leads people to perceive these women as trustful individuals, particularly about donations. Second, Bernarda's discourse assumes personal responsibility, and her words reflect her religious commitment to what she and other Patronas feel is God's project. As time has passed, this moral capital has led the Patronas to become a nodal center that brings together different grassroots organizations concerning issues of migrants' human rights and social justice at both the national and international levels. We next examine how the Patronas' kitchen becomes a place where the collective action of solidarity begins and where a space of transformation for these women occurs.

\section{The kitchen as a place to 'cook' solidarity}

Drawing from feminist geographers' theories on domestic power (Meah 2014, Robson 2006, Christie 2006, Abarca 2006), we argue that for the Patronas, the kitchen becomes a space 
where they transform their lives from one they have to live (in subordination to monotonous household chores carried out in isolation) into a life they choose to live. Abarca (2006) examined the kitchen, food preparation, and meanings among working-class Mexican and MexicanAmerican women. She observed that when the kitchen is conceptualized as space rather than a place, it 'can represent a site of multiple changing levels and degrees of freedom, self-awareness, subjectivity, and agency (Abarca 2006, 20).’

If I had not participated [as a Patrona], my life would have been nothing else than the kitchen. As a Patrona, I was able to leave the kitchen and realize I could do much more. Men sometimes make us feel that we (women) cannot. I never imagined being at a university and having so many students in front of me listening to what I have to say.

Lupe's comment highlights her process of transformation from a state of 'comfort being' to a 'project of becoming.' For feminist geographer Dareen Massey, the difference between these two concepts is that in the first case, women are in a state of simply being, which translates into occupying a stable, fixed, and unchangeable space. In the second case, women 'are in constant state of creation, change and in the process of becoming' (Abarca 2006, 20). This transformational experience is evident in the case of Lupe, a woman in her mid-40s, when she emphasizes that the work of feeding the migrants allowed her to realize that she had the capacity to 'do something more' with her life, including the opportunity to speak at universities about the situation of Central American migrants.

From 2011 onwards, the Patronas have been invited to share their experiences at universities in not only Mexico, but also Central America, the United States, and Europe. In Lupe's case, she has traveled to the US and Europe. In the same quote, Lupe alludes to her work with the migrants, particularly alongside other women, allowing her to leave the kitchen as a physical place, 
where she was conditioned to occupy a socially secondary status from a very young age and to develop it into a space of personal transformation.

Bernarda is a 50-year old woman with elementary education and the eldest daughter of the Romero family. Like Lupe, she considers her work feeding migrants to have transformed her life and has allowed her to transform her traditional role of a peasant woman. This is particularly indicated in the following quote.

Well look, it has changed each of our lives a little because before we were only included in the kitchen of our home, and the only thing we did was prepare food and at four (PM) turn on the TV and lay there watching soap-operas... and now I have no time, not even for us (sic). Yes, it has changed us because thank God, for this job, we have met many people whom we would not have met if we had been inside watching TV and gossiping with the neighbors and friends. Here is where we would spend all our lives and we would die, and that is it.

For the Patronas, cooking has become a project of creation and change, and the kitchen has shifted from a private and isolated space into a public and collective place that serves as a central axis where the collective action of solidarity begins. The emotional work of the Patronas over the last two decades has allowed them to turn the kitchen into a space for mobilization, empathy, and inspiration, as well as to leave behind the image of the kitchen as a secondary, private, and fixed place. Daily life and repetitive activities within the kitchen are transformed into a tool for accumulating experiences and has become an opportunity for self-reflection that has led to knowledge and personal growth over time. This growth is clearly identified in the dozens of interviews analyzed for this study, both nationally and internationally, in which the Patronas' words about the work they perform display an evident evolution. People from all walks of life, particularly university students, want to listen to these women. Becoming the center of public attention has led the Patronas to reflect on what their role is. The following quote by Bernarda captures this concern: 
My throat turned into a knot because I asked myself, "Who am I?" "Why?" And I began to see all the people and all the young people who were there, filling that big auditorium, and one feels "Oh my God! What am I doing here?" And that's when you start to reflect, "It's that people trust you, they believe in you." Thank God I was able to speak; I had a knot in my throat and held my tears back, and yes, but it was very nice, and once I left (the stage), there were many journalists, many interviews...

The Patronas' kitchen is a place where solidarity is metaphorically 'cooked' through each of the chores involved in cooking food for the migrants. The Patronas tell everyone one what to do and how to do it. It is a place where the Patronas become 'the bosses' and where excitement prevails as a preamble for food delivery at the railroad tracks. 'It is a place that is at once both domestic and matriarchally organized, but also public, connected to community life' (Bruzzone 2017, 252).

\section{Discussion and final remarks}

Throughout this paper, we have examined the work of the Patronas. We have paid particular attention to the type of ethics of care that these women provide to the migrants and how this caring work intersects with the participation of Latin American women in social movements. The blurring of public and private spheres was highlighted through the caring activities occurring in the kitchen of the Patronas and the collective action of solidarity that has emerged as a result of these activities. This study also sheds light on the process of transformation that this caring work and mobilizing activities have brought about to the Patrona's lives, their families, and the community. Moreover, by looking at the interplay between women's collective action, ethics of care, and emotional labor in social movements, this study contributes to women's movements in two ways. 
First, by investigating women's identity and their motivations for feeding thousands of Central American migrants for more than two decades, we shed light on the role that emotional work plays in sustaining solidarity movements and in humanizing migration experiences by opposing the hegemonic discourse of migrants' criminalization and commodification. The values of care generate a political resonance in a wide range of national and international sectors. The Patronas have become social leaders as well as 'signifying agents' (Benford and Snow 2000, 613), given that they are 'engaged in the production and maintenance of meaning.' This has allowed them to develop a socio-political project based on the redefinition of values over 'Otherness.' By acting outside the confines of the church, the religious features that initially supported the Patronas' work have transformed into a politicized spirituality.

The expression of 'Thank you, mother' that the Patronas receive from migrants when their sights meet for a few seconds while giving and receiving food provides motivation and strength to continue their work. In this sense, the Patronas' praxis of motherhood is political, which is similar to other Latin American motherist movements such as the mothers of the disappeared Central American migrants on their way through Mexico. The Patronas' caring and emotional work lead them to exert a feminist ethics of care based on trust, reciprocity, and solidarity. Further, the theorization of an ethics of care can also be applied more broadly to other mother-activist movements in Latin America. In these movements, women's participation is not only at the core of their strategies, but, most importantly, gender practices of femininity can be re-signified.

In their narratives, the Patronas depict the vicissitudes of the peasants' reality, but they also depict the strength and determination that many of these communities hold. Three generations of women of the Romero family have been part of the Patronas. Currently, three of doña Leo's grandchildren, who became Patronas from a very early age, are now in college. One of those 
grandchildren is already working on a migrant shelter in Mexico City, and the other two are majoring in areas related to migration. Thus, the Romero family and the community of La Patrona have changed. The Patronas and the community have gained national and international recognition through interviews, news, and documentaries on their work, as well as talks at universities, chats with volunteers, and collaborations with different human rights and migrant organizations. Above all, through their daily labor of feeding migrants, the women of La Patrona experience a reflexive exercise about the meaning of their labor and about whom they are as campesinas (peasant women). They empower themselves through their daily practices to speak and act on behalf of their own bodies and hearts and fully acknowledges their importance in society.

Secondly, this study fills the gap in the literature on women's participation in collective action, particularly women's role as leaders and organizers in solidarity movements and how these movements generate cultural resonance and attract hundreds of volunteers. Unlike the pity that goes along with charity, the Patronas' caring and emotional work revolve around compassion, which leads these women and volunteers to participate in a political practice of solidarity. This practice sets up an extensive web of nurturing social bonds and moral solidarities for migrants who experience extreme social suffering. Thus, while ideological discourse casts the migrants as illegal, and criminalizes and strips the individual of his/her humanity, the Patronas' ethics of care transcends borders by appealing to universal emotions such as solidarity, compassion, and empathy.

Finally, this study helps to improve the understanding of the role of Latin American women's participation in collective action and the role of emotional work in the valuing of life within social movements. The work of the Patronas affords us the opportunity to analyze ethics of care in solidarity movements by examining areas such as identities, emotions, and motivations. 
The agency of these women from a small village in rural Mexico is both locally rooted and globally oriented. The Patronas repeatedly express their identity as 'campesinas,' but their mobilization lies at the heart of national and global resistance to the commodification of human mobility. Feeding migrants on their path and knowing their travel conditions serve as a reflection of the human affinity toward the fragility and vulnerability of those who have little or almost nothing, like the Patronas. Despite the adversity, the Patronas, migrants, and volunteers manage to generate spaces of resistance, action, and change. 


\section{References}

Abarca, Meredith E. 2006. Voices in the Kitchen: Views of Food and the World from WorkingClass Mexican an Mexican American Women. College Station, TX: Texas A\&M University Press.

Abbruzzese, Teresa V, and Gerda Wekerle, R. 2011. "Gendered Spaces of Activism in Exurbia: Politicizing an Ethic of Care from the Household to the Region." Frontiers: A Journal of Women Studies 32 (2):140-169. doi: 10.5250/fronjwomestud.32.2.0140.

Aguilar-Rivera, N., D.A. Rodriguez L, V. Enriquez R, A. Castillo M, and A. Herrera S. 2012. "The Mexican Sugarcane Industry: Overview, Constraints, Current Status and LongTerm Trends." Sugar Tech 14 (3):207-222.

Andrews, Abigail. 2014. "Women's Political Engagement in a Mexican Sending Community: Migration as Crisis and the Struggle to Sustain an Alternative." Gender \& Society 28 (4):584-608.

Arenas, Iván. 2015. "The mobile politics of emotions and social movement in Oaxaca, Mexico." Antipode 47 (5):1121-1140.

Bejarano, Cynthia L. 2002. "Las Super Madres de Latino America: Transforming Motherhood by Challenging Violence in Mexico, Argentina, and El Salvador." Frontiers: A Journal of Women Studies 23 (1):126-150.

Benford, Robert D., and David A. Snow. 2000. "Framing Processes and Social Movements: An Overview and Assessment." Annual Review of Sociology 26:611-639.

Borland, Elizabeth. 2007. "Quotidian Disruption and Women's Activism in Times of Crisis, Argentina 2002-2003." Gender \& Society 21 (5):700-722.

Bosco, Fernando J. 2006. "The Madres de Plaza de Mayo and Three Decades of Human Rights' Activism: Embeddedness, Emotions, and Social Movements." Annals of the Association of American Geographers 96 (2):342-365.

Brennan, Geoffrey. 2004. The Economy of Esteem: An Essay on Civil and Political Society. Oxford and New York: Oxford University Press.

Brickell, Katherine. 2012. "'Mapping' and 'doing' critical geographies of home." Progress in Human Geography 36 (2):225-244.

Bruzzone, Mario. 2017. "Respatializing the domestic: gender, extensive domesticity, and activist kitchenspace in Mexican migration politics." Cultural Geographies 24 (2):247-263.

Butler, Judith. 2004. Precarious life: The powers of mourning and violence: Verso. 
Casillas, Rodolfo. 2011. "The Dark Side of Globalized Migration: The Rise and Peak of Criminal Networks-The Case of Central Americans in Mexico." Globalizations 8 (3):295-310. doi: 10.1080/14747731.2011.576846.

Chinchilla, N., and Liesl Hass. 2007. "'De Protesta a Propuesta: The Contributions and Challenges of Latin American Feminism'." In Latin America after neoliberalism: Turning the tide in the 21 st century, edited by E. Hershberg and F. Rosen. New York: New Press.

Chinchilla, Norma Stoltz, Nora Hamilton, and James Loucky. 2009. "The Sanctuary Movement and Central American Activism in Los Angeles." Latin American Perspectives 36 (6):101-126. doi: 10.1177/0094582x09350766.

Christie, Maria E. 2006. "Kitchenspace: Gendered territory in central Mexico." Gender, Place \& Culture 13 (6):653-661.

Dunn, Jennifer L. 2004. "The Politics of Empathy: Social Movements and Victim Repertoires " Sociological Focus 37 (3):235-250.

Green, Linda. 2011. "The Nobodies: Neoliberalism, Violence, and Migration." Medical Anthropology: Cross-Cultural Studies in Health and Illness 30 (4):366-385.

Hagan, Jacqueline 2008. Miracle Migration: Faith, Hope and the Undocumented Journey. Cambridge, MA: Harvard University Press.

Hankivsky, Olena. 2014. "Rethinking Care Ethics: On the Promise and Potential of an Intersectional Analysis." The American Political Science Review 108 (2):252-264.

Hanson, Susan. 2010. "Gender and mobility: new approaches for informing sustainability." Gender, Place \& Culture 17 (1):5-23.

Hercus, Cheryl. 1999. "Identity, Emotion, and Feminist Collective Action." Gender \& Society 13 (1):34-55.

Hondagneu-Sotelo, Pierrette, Genelle Gaudinez, Hector Lara, and Billie C. Ortiz. 2004. "'There's a Spirit that Transcends the Border': Faith, Ritual, and Postnational Protest at the U.S.Mexico Border." Sociological Perspectives 47 (2):133-159. doi: 10.1525/sop.2004.47.2.133.

Jaggar, Alison M. 1989. "Love and knowledge: Emotion in feminist epistemology." Inquiry 32 (2):151-176. doi: 10.1080/00201748908602185.

Jaquette, J. S., ed. 2009. Feminist agendas and democracy in Latin America. Durham: Duke University Press.

Jasper, James M. . 2011. "Emotions and Social Movements: Twenty Years of Theory and Research." Annual Review of Sociology 37:285-303. 
Jelin, Elizabeth. 1994. "The politics of memory: the human rights movement and the construction of democracy in Argentina." Latin American Perspectives 21 (2):38-58.

Lawson, Victoria. 2007. "Geographies of Care and Responsibility." Annals of the Association of American Geographers 97 (1):1-11.

Lichbach, Mark Irving. 1996. The Cooperator's Dilemma. Ann Arbor: The University of Michigan Press.

Maier, Elizabeth, and Nathalie Lebon, eds. 2010. Women's Activism in Latin America and the Caribbean: Engendering Social Justice, Democratizing Citizenship. New Brunswick, NJ: Rutgers University Press.

Martínez, Oscar. 2013. The Beast: Riding the Rails and Dodging Narcos on the Migrant Trail. Brooklyn, NY: Verso

Meah, Angela. 2014. "Reconceptualizing power and gendered subjectivities in domestic cooking spaces." Progress in Human Geography 38 (5):671-690.

Migrantes, Red de Documentación de las Organizaciones Defensoras de. 2016. Migración en tránsito por México: rostro de una crisis humanitaria internacional. Informe 2015.

Oosterlynck, Stijn, Maarten Loopmans, Nick Schuermans, Joke Vandenabeele, and Sami Zemni. 2016. "Putting flesh to the bone: looking for solidarity in diversity, here and now." Ethnic and Racial Studies 39 (5):764-782. doi: 10.1080/01419870.2015.1080380.

Paris, Maria Dolores. 2017. Violencias y migraciones centroamericanas en Mexico. Mexico: El Colegio de la Frontera Norte.

Pile, Steve. 2010. "Emotions and affect in recent human geography." The Royal Geographical Society 35 (1):5-20.

Power, Margaret, and Julie A Charlip. 2009a. On solidarity. Sage Publications Sage CA: Los Angeles, CA.

Power, Margaret, and Julie A. Charlip. 2009b. "On Solidarity." Latin American Perspectives 36 (6):3-9.

Robson, Elsbeth. 2006. "The 'kitchen' as women's space in rural Hausaland, northern Nigeria." Gender, Place \& Culture 13 (6):669-676.

Rodriguez Castro, Laura, Barbara Pini, and Sarah Baker. 2016. "The global countryside: peasant women negotiating, recalibrating and resisting rural change in Colombia." Gender, Place \& Culture 23 (11):1547-1559.

Salzinger, Leslie. 2003. Gender in Production: Making Workers in Mexico's Global Factories. Los Angeles, CA: University of California Press. 
Scholz, Sally J. 2008. Political Solidarity. University Park: Penn State University Press.

Schroeder, Kathleen. 2006. "A Feminist Examination of Community Kitchens in Peru and Bolivia." Gender, Place \& Culture 13 (6):663-668.

Schütte, Stefan 2014. "Living with patriarchy and poverty: women's agency and the spatialities of gender relation in Afghanistan." Gender, Place \& Culture 21 (9):1176-1192.

Sharp, Joanne. 2009. "Geography and gender: what belongs to feminist geography? Emotion, power and change." Progress in Human Geography 33 (1):74-80.

Stephen, Lynn. 1997. Women and Social Movements in Latin America. Austin: University of Texas Press.

Taylor, Verta. 1999. "Gender and Social Movements: Gender Processes in Women's Self-Help Movements." Gender \& Society 13 (1):8-33.

Van Wijnendaele, Barbara. 2014. "The Politics of Emotion in Participatory Processes of Empowerment and Change." Antipode 46 (1):266-282.

Vogt, Wendy A. 2013. "Crossing Mexico: Structural violence and the commodification of undocumented Central American migrants." American Ethnologist 40 (4):764-780.

Wilkinson, Iain, and Arthur Kleinman. 2016. A Passion for Society: How We Think About Human Suffering Oakland, California: University of California Press.

Wright, Melissa W. 2010. "Geography and gender: Feminism and a feeling of justice." Progress in Human Geography 34 (6):818-827.

Wright, Melissa W. 2005. "Paradoxes, Protests and the Mujeres de Negro of Northern Mexico." Gender, Place \& Culture 12 (3):277-292. doi: 10.1080/09663690500202376.

Wright, Melissa W. 2008. "Gender and geography: knowledge and activism across the intimately global." Progress in Human Geography 33 (3):379-386.

Wright, Melissa W. 2011. "National Security versus Public Safety: Feminicide, Drug Wars, and the Mexican State." In Accumulating Insecurity: Violence and Dispossesion in the Making of Everyday Life, edited by Shelley Feldman. Athens, GA: University of Geogria Press.

Wright, Melissa W. 2014. "The Gender, Place and Culture Jan Monk Distinguished Annual Lecture: Gentrification, assassination and forgetting in Mexico: a femenist Marxist tale." Gender, Place \& Culture 21 (1):1-16. 
' During the interviews, several of the Patronas emphasize the great pleasure they obtain from the gratitude received from Central American migrants when they say 'Thank you, Mother.' The use of 'mother' and 'grandmother' is affectionately directed to women in the region depending on their age and their role as caregivers.

ii Las Patronas: Women who help complete strangers on a passing train

https://www.youtube.com/watch?v=yYbjSYgw3sk

La Patronas: The Mexican women helping migrants

http://www.bbc.com/news/world-latin-america-28193230

Las Patronas: 20 años de ayuda al prójimo

http://www.cnn.com/videos/spanish/2015/02/17/cnnee-alis-mexico-las-patronas-20yr-humanitarian-labor.cnn

Mexico women's generosity helps Central American migrants along perilous route

http://www.barriozona.com/migrants_central_american_las_patronas_veracruz_mexico_women_food_trains.html

NPR: Unaccompanied Central American minors and Las Patronas

http://www.npr.org/sections/parallels/2014/07/24/334494493/who-are-the-kids-of-the-migrant-crisis

Universo PYME: Las Patronas

https://www.youtube.com/watch?v=cY9pDJX0Z0Q

La Patrona por Javier García/SACBE productions

https://www.youtube.com/watch?v=huO7a24q0B4

Las Patronas: Héroes sin Fronteras

https://www.youtube.com/watch?v=6wvj9My6LyI

Las Patronas: Mexican Women Help Border Kids reach the US.

http://www.nbcnews.com/storyline/immigration-border-crisis/las-patronas-mexican-women-help-border-kids-reachu-s-n158241

Asociación Cuauhtémoc, entrevista a Las Patronas

https://www.youtube.com/watch?v=8_f-LYbt7Xo

Llevate mis amores: Entrevista con Chelis López

https://www.youtube.com/watch?v=KFZ1Onu5Nk4

Las patronas: Educación Popular - Brasil

https://www.youtube.com/watch?v=DWcRz9AaT4U

iii De Nadie (2006); Llevate mis amores (2013); El tren de las moscas (2011). 